\title{
Preface: Special Issue-College Experiences for Students with Autism Spectrum Disorder
}

\author{
Scott L. J. Jackson ${ }^{1}$ (1) $\cdot$ Logan Hart ${ }^{1} \cdot$ Fred R. Volkmar ${ }^{1}$
}

Published online: 31 January 2018

(c) Springer Science+Business Media, LLC, part of Springer Nature 2018

Thirty years ago it was rare for a student with autism spectrum disorder (ASD) to enter college. However, over the past decades with the increased awareness and detection of ASD in children with average or above average intellectual abilities (Christensen et al. 2016) and with the improved provisions of effective, evidence-based treatments (Reichow and Volkmar 2011) many students with ASD are now seeking enrollment in college (Volkmar et al. 2017). In the USA alone there are roughly 550,000 children with ASD who will be transitioning into adulthood over the next decade (Buescher et al. 2014), and it is expected that approximately $45 \%$ of these emerging adults will enroll in a university, college, or technical/vocational school in the coming years (Newman et al. 2011).

This is a promising trend, as completion of a post-secondary degree is a significant predictor of positive adult outcomes in ASD populations, impacting the likelihood that an individual will be able to find employment, obtain financial independence, and live independently. However, students with ASD have a lower likelihood of completing their degree (38.8\%) compared to students from the general population $(52.4 \%)$ and those with disabilities in general (40.7\%; Newman et al. 2011).

College presents new challenges for these students as well as for college support personnel. There are major changes in both the way education is provided and in the nature and availability of support services (Reichow and Volkmar 2011). While difficulties adapting to the increased academic challenges of post-secondary education may contribute to the discrepancy in rate of degree completion, non-academic factors are likely to have a greater impact. For students with ASD these factors include disorder-related social, communicative, sensory, routine adherence, and executive functioning

Scott L. J. Jackson

scott.jackson@yale.edu

1 Child Study Center, School of Medicine, Yale University, 230 South Frontage Road, New Haven, CT 06520, USA impairments, and the impact of these impairments on the students' ability to adapt to the changing environment, social demands, fluctuating schedules, and management of daily living responsibilities associated with collegiate life (Volkmar et al. 2017).

Findings from a systematic review of the literature describing the experiences of college students with ASD (Gelbar et al. 2014) have lent support to the notion that non-academic issues are underlying many of the difficulties experienced by this student population. Based on 20 articles, with a cumulative sample of 69 current and former college students with ASD, the most commonly reported experiences were related to struggles with anxiety, loneliness, and depression (respectively). Since the release of the Gelbar et al. (2014) review, approximately ten additional articles on the topic of the needs and/or experiences of post-secondary students with ASD have been published. While this uptick in interest is promising, the general dearth of literature on this topic significantly limits both our understanding of the challenges impacting the ability of many students with ASD from achieving their full potential in post-secondary academic settings, and our insight into how these challenges can be addressed. This lack of information also poses challenges for college support personnel who themselves must adapt to the new challenges students with ASD present in the college environment.

This Special Issue of the Journal of Autism and Developmental Disorders addresses some of these issues. It includes articles covering the topics of self-reported experiences from college students with ASD, explorations of bullying prevalence and underlying issues, parental insight into ways in which we can support students with ASD to give them the best opportunity for success in post-secondary academic settings, and finally a review of evidence-based programs for college students with ASD and reports on emerging support options that are currently being evaluated in the field. While not an exhaustive compilation of the issues concerning college students with ASD, these articles will make strong 
additions to the current literature-base on this subject, and we hope that they will inspire others to consider incorporating research on this topic into their own work.

The first two articles to appear in this Special Issue are findings from online surveys distributed to college students with ASD primarily from the USA (Jackson et al. 2018) and Australia (Anderson et al. 2018). Surveying 104 college students with ASD in combination, the publication of these studies alone represent a marked increase in the amount of first-hand insight on this topic available in the extant literature. Although the samples come from different parts the world their findings are very similar. Anderson and colleagues find that most of the self-reported strengths of the participants in their study are academically oriented (e.g. creative thinking, detail orientation, strong memory), meanwhile Jackson and colleagues find that only a minority of their participants (21.4\%) reported feeling uncomfortable with their academic workloads. Both studies also mirrored previous findings of frequent struggles with mental health issues. The majority of college students with ASD from the Anderson et al. study reported anxiety (90.2\%), depression (70.7\%) and loneliness (61\%) to be 'moderate' to 'big' concerns of theirs, while the participants in the Jackson et al. study averaged 'severe' to 'extremely severe' symptom expression of depression, anxiety and stress (as reported by the Depression Anxiety and Stress Scale) and 75\% of this sample reported feeling isolated, left out, or lacking companionship 'some of the time' to 'often'. Perhaps the most concerning finding between these two studies was the frequency with which lifetime suicidal behaviors (74.6\%) were reported by the participants from the Jackson et al. study, and the fact that $17.9 \%$ of their sample reported that it was 'likely' or 'very likely' that they were going to attempt suicide in the future.

The next article focuses on an important clinical problem-the experiences of bullying for college students with ASD. Bullying has been a well-documented issue for youth with ASD, even as compared to students with other disabilities (e.g. Sreckovic et al. 2014), but as with most things related to the experiences of college students with ASD there is a paucity of information available on this issue. DeNigris et al. (2018) compares the bullying experiences of 22 college students with ASD to 15 college students without ASD, and examines whether reduced cognitive empathy (and a so-called 'double empathy problem') is associated with increased risk of being bullied for students with ASD (DeNigris et al. 2018). In line with the prevalence of bullying experiences reported in the previous two articles (35.7 and $24.4 \%$, respectively), they find that bullying in college was only experienced by $21 \%$ of the students with ASD from their study. While this prevalence rate was not found to be statistically significantly higher than the prevalence of bullying experiences from their non-ASD sample (7\%), clearly more examinations of this topic in larger samples are needed. Additionally, as both student groups reported similar levels of cognitive empathy the authors were unable to produce any evidence to support the idea that a 'double empathy problem' was contributing to bullying experiences of college students with ASD.

The next several articles shift their focus to the accommodations and services provided for college students with ASD: where they are succeeding, what needs they are failing to meet for this unique student population, and what programs are in existence that have been evaluated specifically for their effectiveness for students with ASD. Sarret reports on first-hand experiences and recommendations for postsecondary accommodations and services in 66 adults with ASD (Sarrett 2018). Utilizing a combination of surveys and online focus groups, the participants from this study produced mixed feedback regarding their satisfaction with the services they utilized as post-secondary students. Roughly two-thirds of the participants who utilized services at school reported that they met their expectations. Meanwhile, for the remaining participants, dissatisfaction with accommodations were due to a seemingly primary focus on academics (failing to address social, sensory, and psychiatric needs), inconsistent implementation of services, and poor awareness of accommodation options by school faculty and staff. Providing recommendations for post-secondary institutions based on the feedback from the study participants, Sarrett suggests the inclusion of neurodiverse spaces, and mentorship programs to be offered alongside conventional accommodations to better address the needs of students with ASD.

The next two articles report on specific programs, including evaluations of their ability to improve collegiate outcomes for this population. Lucas and James (2018) evaluate a specialist mentoring program that examines benefits for students with ASD as well as students with mental health conditions, and utilizes a mixed-methods methodology incorporating feedback from the mentors and the mentees (Lucas and James 2018). The inclusion of the mental health condition control group not only offers the opportunity to elucidate benefits that may be specific to the needs of students with ASD, but considering the high occurrence of mental health issues reported in the Jackson et al. (2018) and Anderson et al. reports, a service that can cater to both of these conditions will have utility for the majority of college students with ASD. The results of their investigation supported the benefits of the specialist mentoring program for social and emotional development in their participants with ASD. Further, based on thematic analyses they suggest that the quality and personalization of the relationship between the mentor and mentee was of critical importance in predicting the impact of the program on the mentored student. The utility of mentorship programs is further addressed in a letter to the editor included in this issue (Płatos and Wojaczek 
2018), which recommends the expansion of peer-mediated interventions into older ASD populations (such as college students and high school students preparing for the transition to college).

The second program evaluation article included in this Special Issue describes a writing improvement program (Jackson et al. 2018). Designed to provide instruction following the Self-Regulated Strategy Development model, the efficacy of this ten-session writing improvement program was examined on three students with ASD who had previously struggled with a college writing course (previously receiving a failing grade, withdrawing due to struggles, or receiving a grade of "C") and incorporated a multiple baseline assessment to evaluate the program's success. All three of the participants were not only able to improve their writing abilities as assessed by a writing skill rubric, but these improvements remained during follow-up evaluations and each student significantly improved their performance in the college writing course they had previously struggled with (from failing to an "A-", from withdrawing to a "B+", and from a "C" to a "B").

The Special Issue concludes with a systematic review of evidence-based services for college students with ASD that have had explicit evaluations of their efficacy in the literature (similar to the two preceding articles), and an article describing parental perceptions of the challenges facing college students with ASD and their recommendations for services to address those challenges. For the systematic review (Kuder and Accardo 2017) eight studies evaluating programs for college students with ASD were identified and examined. Based on their review, the authors indicate that while there is a growing research-base for programs to meet the needs of students with ASD, the findings regarding their efficacy have been mixed and primarily based on limited sample sizes. In the final paper in this Issue Elias and White (2018) review feedback from 52 parents of post-secondary students with ASD and 47 parents of post-secondary students with attention deficit hyperactivity disorder (ADHD). Elias and White note that the parent-reported challenges and recommended services for students with ASD were distinguishable from those with ADHD, with the parents of students with ASD endorsing unique challenges with emotion regulation, self-advocacy, and managing adaptive skills. As a result, the authors suggest distinct support options for students with ASD, with a particular emphasis on transition programs designed to improve social interaction and independent living skills. Additionally, they recommend that these programs are initiated before the student leaves for school, so that parents can still be involved in the process and the skills can be in place before the student steps foot on campus. Complementing these recommendations are the findings from a comparable article on parent-reported challenges for college students with ASD (Anderson and Butt
2017), and a preliminary examination of a college transition program (White et al. 2017) designed specifically for the needs of students with ASD (the Stepped Transition in Education Program for Students with ASD), both of which were published in the October 2017 issue of JADD.

In conclusion, it is clear that the available literature on the topic of the experiences and needs of college students with ASD is expanding as is the level of need for these students and their supporters. Our understanding of this topic is far from complete and further work is still needed in several areas: (1) additional large sample studies of first-hand experiences of students with ASD to increase generalizability of findings; (2) evaluations of programs designed to meet the specific needs of this population; (3) identification of evidence-based practices that can be used both in high school and college settings to facilitate the transition of students to college and improve their vocational success following college; and (4) examinations of insight from the professionals at post-secondary institutions who are working with these students on a day-to-day basis. Lastly, we need to find new and more effective ways of implementing outreach programs for students, parents, and teachers at high schools so areas of need can be addressed before they present as problems in the college setting.

We want to thank all of those who contributed to this Special Issue for their hard work and dedication to this topic, as well as all of those who participated in these studies for being willing to share their experiences and perspectives so that we may improve the outcomes of individuals with ASD embarking into post-secondary academic settings in the years to come.

Funding Current funding for Scott L. J. Jackson is from NIMH T32 MH018268.

\section{References}

Anderson, C., \& Butt, C. (2017). Young adults on the autism spectrum at college: Successes and stumbling blocks. Journal of Autism and Developmental Disorders, 47(10), 3029-3039.

Anderson, H., Carter, M., \& Stephenson, J. (2018). Perspectives of university students with autism spectrum disorder in Australia. Journal of Autism and Developmental Disorders. https://doi. org/10.1007/s10803-017-3257-3.

Buescher, A. V., Cidav, Z., Knapp, M., \& Mandell, D. S. (2014). Costs of autism spectrum disorders in the United Kingdom and the United States. JAMA Pediatrics, 168(8), 721-728.

Christensen, D. L., Baio, J., Braun, K. V. N., Bilder, D., Charles, J., Constantino, J. N., ... Lee, L. C. (2016). Prevalence and characteristics of autism spectrum disorder among children aged 8 yearsAutism and Developmental Disabilities Monitoring Network, 11 sites, United States, 2012. MMWR Surveillance Summaries, 65(3), 1-23. https://doi.org/10.15585/mmwr.ss6503a1.

DeNigris, D., Brooks, P. J., Obeid, R., Alarcon, M., Shane-Simpson, C., \& Gillespie-Lynch, K. (2018). Bullying and identity development: Insights from autistic and non-autistic college students. 
Journal of Autism and Developmental Disorders. https://doi. org/10.1007/s10803-017-3383-y.

Elias, R., \& White, S. W. (2018). Autism goes to college: Understanding the needs of a student population on the rise. Journal of Autism and Developmental Disorders. https://doi.org/10.1007/ s10803-017-3075-7.

Gelbar, N. W., Smith, I., \& Reichow, B. (2014). Systematic review of articles describing experience and supports of individuals with autism enrolled in college and university programs. Journal of Autism and Developmental Disorders, 44(10), 2593-2601.

Jackson, L. G., Duffy, M. L., Brady, M. P., \& McCormick, J. (2018). Effects of learning strategy training on the writing performance of college students with asperger's syndrome. Journal of Autism and Developmental Disorders. https://doi.org/10.1007/s1080 3-017-3170-9.

Jackson, S. L. J., Hart, L., Brown, J. T., \& Volkmar, F. R. (2018). Brief Report: Self-reported academic, social, and mental health experiences of post-secondary students with autism spectrum disorder. Journal of Autism and Developmental Disorders. https:// doi.org/10.1007/s10803-017-3315-x.

Kuder, S. J., \& Accardo, A. (2017). What works for college students with autism spectrum disorder. Journal of Autism and Developmental Disorders. https://doi.org/10.1007/s10803-017-3434-4.

Lucas, R., \& James, A. I. (2018). An evaluation of specialist mentoring for university students with autism spectrum disorders and mental health conditions. Journal of Autism and Developmental Disorders. https://doi.org/10.1007/s10803-017-3303-1.

Newman, L., Wagner, M., Knokey, A. M., Marder, C., Nagle, K., Shaver, D., \& Wei, X. (2011). The post-high school outcomes of young adults with disabilities up to 8 years after high school: A report from the National Longitudinal Transition Study-2 (NLTS2). NCSER 2011-3005. National Center for Special Education Research.

Płatos, M., \& Wojaczek, K. (2018). Broadening the scope of peermediated intervention for individuals with autism spectrum disorders. Journal of Autism and Developmental Disorders. https:// doi.org/10.1007/s10803-017-3429-1.

Reichow, B., \& Volkmar, F. R. (2011). Evidence-based practices in autism: Where we started. In: B. Reichow (Ed.) Evidence-based practices and treatments for children with autism (pp. 3-24). New York: Springer.

Sarrett, J. C. (2018). Autism and accommodations in higher education: Insights from the autism community. Journal of Autism and Developmental Disorders. https://doi.org/10.1007/s1080 3-017-3353-4.

Sreckovic, M. A., Brunsting, N., \& Able, H. (2014). Victimization of students with autism spectrum disorder: A review of prevalence and risk factors. Research in Autism Spectrum Disorders, 8(9), 1155-1172. https://doi.org/10.1016/j.rasd.2014.06.004.

Volkmar, F. R., Jackson, S. L., \& Hart, L. (2017). Transition issues and challenges for youth with autism spectrum disorders. Pediatric Annals, 46(6), e219-e223.

White, S. W., Elias, R., Capriola-Hall, N. N., Smith, I. C., Conner, C. M., Asselin, S. B., ... Mazefsky, C. A.(2017). Development of a college transition and support program for students with autism spectrum disorder. Journal of Autism and Developmental Disorders, 47(10), 3072-3078. 